\title{
PREVALÊNCIA DO USO DE ANFETAMINAS POR CAMINHONEIROS
}

\author{
Tayná Oliveira BELAN, Cristiano Guilherme Alves de OLIVEIRA, Sérgio Henrique de Mattos \\ MACHADO*, Patrícia de Souza BRANDÃO \& João Romário Gomes da SILVA
}

Universidade Iguaçu, Campus V. Itaperuna, Rio de Janeiro, Brasil.

*Autor para correspondência: sergiojf@ig.com.br

DOI: http://dx.doi.org/10.18571/acbm.141

\section{RESUMO}

Os motoristas de cargas muitas vezes fazem o transporte por longos percursos e com tempo estabelecido para entrega, enfrentando vias rodoviárias em péssimas condições. Diante de tal situação, muitos fazem uso de drogas com o objetivo de reduzir o sono. O abuso de drogas psicoativas, dentre elas as anfetaminas, podem ocasionar prejuízos na habilidade e atenção do motorista, aumentando os riscos de envolvimento em acidentes. Este projeto de pesquisa teve como objetivo analisar a prevalência do uso de anfetaminas por motoristas de caminhões, pesquisando os efeitos toxicológicos das anfetaminas, os riscos e benefícios do consumo de anfetaminas por motoristas profissionais e analisando o perfil socioeconômico, comorbidades, uso de bebidas alcoólicas e tabaco; o uso de anfetaminas, e sua frequência e origem de obtenção. Para melhor entendimento, foram entrevistados 80 caminhoneiros, sendo 40 em 2013 e 40 em 2016, para visualização das mudanças ocorridas após a legislação sobre a necessidade de exames laboratoriais para presença de drogas e as delimitações da comercialização de anfetaminas. Através dos resultados encontrados, pode-se observar a não ocorrência de uma redução significativa da prevalência do uso de anfetaminas entre os anos de 2013 e 2016.

Palavras-chave: Anfetaminas; Caminhoneiros; Abuso de drogas

\begin{abstract}
Freight drivers often transport for long journeys and have a set time for delivery, facing poor road conditions. Faced with such a situation, many make use of drugs with the goal of reducing sleep. The abuse of psychoactive drugs, among them amphetamines, can cause impairments in the skill and attention of the driver, increasing the risks of involvement in accidents. This research project aimed to analyze the prevalence of amphetamines use by truck drivers, investigating the toxicological effects of amphetamines, the risks and benefits of amphetamine use by professional drivers and analyzing socioeconomic profile, comorbidities, use of alcoholic beverages and tobacco; The use of amphetamines, and their frequency and source of achievement. For a better understanding, 80 truck drivers were interviewed, 40 in 2013 and 40 in 2016, in order to see the changes that occurred after the legislation on the need for laboratory tests for drugs and the delimitations of the commercialization of amphetamines. Through the results found, it is possible to observe the non-occurrence of a significant reduction of the prevalence of the use of amphetamines between the years of 2013 and 2016.
\end{abstract}

Keywords: Amphetamines; Truck drivers; Drug abuse.

\section{Introdução}

Todas as atividades da sociedade atual dependem do sistema de trânsito e de transportes, influindo direta e indiretamente na vida das pessoas. No caso do Brasil, onde a malha rodoviária é o principal meio de transporte de cargas e de pessoas, as rodovias são fundamentais para a 
economia do país, permitindo a movimentação de pessoas e de seus bens. Estima-se que 96\% das distâncias percorridas no Brasil sejam pelo modal rodoviário, 1,8\% por ferrovias e metrôs e o restante por hidrovias e meios aéreos. No que se refere às cargas, $64 \%$ são transportadas através de rodovias, $21 \%$ em ferrovias, $12 \%$ em hidrovias e o restante por gasodutos/oleodutos, ou meios aéreos (HIRATSUKA, 2009).

O setor de transportes de cargas no Brasil emprega mais de quatro milhões de pessoas, existindo uma frota nacional de veículos de 1,9 milhão de caminhões, não havendo dados precisos sobre o número exato de caminhoneiros, sendo estimado, no entanto, que mais de um milhão de pessoas trabalhem no setor de cargas, dentre os quais, 700 mil são caminhoneiros cooperativados ou autônomos (KNAUTH et al., 2012).

O transporte de cargas é responsável por grande parte do escoamento de mercadorias no país, sendo a principal forma de transporte utilizada na área agrícola, industrial e de pessoas, desempenhando, portanto, um papel essencial na vida econômica da nação. No entanto, tal situação acaba ocasionando um grave problema, que são os acidentes de trânsito, que apresentam índices elevados (ZEFERINO, 2004).

Uma das principais causas de acidente fatais envolvendo motoristas de carros ou caminhões é dormir ao volante. Segundo Wendler et al. (2003), motoristas que dormiram menos de 5 horas em um período de 24 horas são mais propensos a envolverem-se em acidentes relacionados a sono ao volante, sendo estes mais frequentes durante a noite, em rodovias, com o motorista sozinho. No que se refere aos caminhões, dirigi-los é uma tarefa complexa, que envolve vigilância, exploração visual, tomada de decisões, controle motor sensorial e avaliação de risco, sendo grandes as chances de acidentes quando estas funções não estão presentes.

Os motoristas de cargas muitas vezes fazem o transporte por longos percursos e com tempo estabelecido para entrega, muitas vezes prejudicado pela deterioração das vias rodoviárias em péssimas condições. Diante de tal situação, muitos fazem uso de medicamentos ou drogas ilícitas com o objetivo de reduzir o sono. Estas drogas psicoativas podem ocasionar prejuízos na habilidade e atenção do motorista, aumentando os riscos de envolvimento em acidentes (WENDLER et al., 2003).

O indivíduo que faz uso de anfetaminas consegue realizar atividades por um tempo maior, com a sensação de menor cansaço, pois nas primeiras horas a sensação de bem-estar é grande. No entanto, após esses efeitos, torna-se irritável, deprimido e com sono incontrolável, podendo dormir ao volante (MOREIRA; GADANI, 2009).

Diante dos altos índices de acidentes fatais envolvendo caminhoneiros nas estradas relacionados ao fato de dormirem ao volante, o presente estudo teve como objetivo analisar a prevalência do uso de anfetaminas por este grupo profissional.

\section{Resultados}

Tendo a delimitação da comercialização de anfetaminas que determina procedimentos no uso restrito de inibidores de apetite. Tal artigo traz à luz um estudo de caráter descritivo no âmbito de tentar elucidar se houve uma mudança no perfil da utilização de rebites após deliberação e mudança do comércio e utilização de anfetaminas.

Analisou-se um total de 80 caminhoneiros divididos entre duas etapas, antes da delimitação da comercialização de anfetaminas, RDC 50/14, sendo um total de 40 caminhoneiros no ano de 2013 e 40 caminhoneiros na segunda pesquisa após entrar em vigor a Portaria 116 do Ministério do Trabalho em 2016.

Após a realização da pesquisa, obtiveram-se os seguintes resultados que descrevem a amostra. $15(18,75 \%)$ possuíam idade inferior a 30 anos; $14(17,5 \%)$ possuíam entre 31 e 40 anos; $25(31,25 \%)$ possuíam entre 41 a 50 anos; 19 (23,75\%) aos 51 e 60 anos: e sete $(8,75 \%)$ pessoas possuíam mais de 60 anos de idade. Todos do sexo masculino. 
Sobre a naturalidade, 34 (42,5\%) motoristas responderam ser do município de Bom Jesus do Itabapoana/RJ; 29 (36,25\%) São de São José do Calçado/ES; 11(13,75\%) são de Vitória/ES; e seis $(7,5 \%)$ são do Rio de Janeiro/RJ. Quanto à sua etnia, $23(28,75 \%)$ se declararam brancos, 16 20(\%) afirmaram serem negros; 27 (33,75\%) são amarelos; e $14(17,5 \%)$ pardos.

Quanto à escolaridade, oito $(10 \%)$ afirmaram nunca ter estudado; $42(52,5 \%)$ completaram somente o primeiro segmento do ensino fundamental; $21(26,25 \%)$ possuem o ensino fundamental completo; e nove $(11,25 \%)$ o ensino médio completo.

Em relação ao tempo de profissão $29(36,25 \%)$ motoristas possuem entre 2 a 9 anos; entre 10 a 20 anos obtiveram-se 27 (33,75\%) motoristas; 10 (12,5\%) têm-se entre 21 a 29 anos; e 23 $(28,75 \%)$ entre 30 a 41 anos. Dentre eles 41(51,25\%) são contratados; 37 (\%) são autônomos; e dois aposentados.

Questionados sobre a origem de suas viagens, 44 (55\%) haviam saído de Cachoeiro do Itapemirim/ES; 25 (31,25\%) de Vitória/ES; oito (10\%) do Paraná; e três $(3,75 \%)$ do Rio Novo do Sul/ES, deles $46(57,5 \%)$ tinha São Paulo/SP como destino; seis $(7,5 \%)$ para Vitória/ES; 17 $(21,25 \%)$ se dirigiam para o Paraná; e 11(13,75\%) para o Rio de Janeiro/RJ.

Perguntados sobre a quantidade de horas que costumam dirigir direto, $16(20 \%)$ afirmaram 4 horas; $16(20 \%)$ declararam 5 horas; $10(12,5 \%)$ disseram 6 horas; quatro (5\%) dirige por 7 horas; sete $(8,75 \%)$ por 8 horas; três $(3,75 \%)$ por 9 horas; $12(15 \%)$ por 10 horas; quatro $(5 \%) 11$ horas; sete $(8,75 \%)$ por 12 horas: e um $(1,25 \%)$ por 13 horas.

Ao serem perguntados sobre serem portadores de alguma doença, $27(33,75 \%)$ afirmaram ser hipertensivos; seis $(7,5 \%)$ declararam ser diabéticos; sete $(8,75 \%)$ se apresentaram como estressados; 40 (50\%) afirmaram não obter nenhum problema de saúde, conforme o gráfico da figura 1:

\section{Comorbidades}

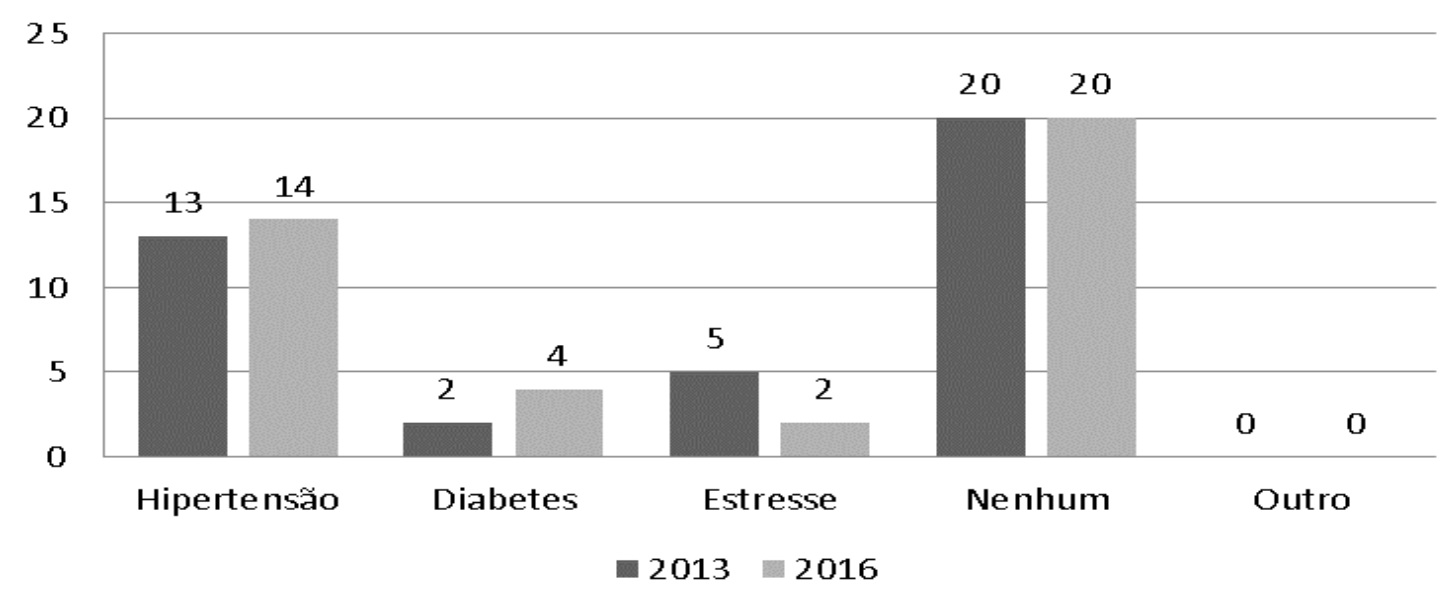

Figura 1: Motoristas portadores de alguma comorbidade.

Ao serem questionados se fazem uso de medicamentos. 35 (43,75\%) responderam afirmativamente; enquanto $45(56,25 \%)$ negaram a utilização de medicamento, conforme representado pelo gráfico da figura 2: 


\section{Faz uso de medicamentos}

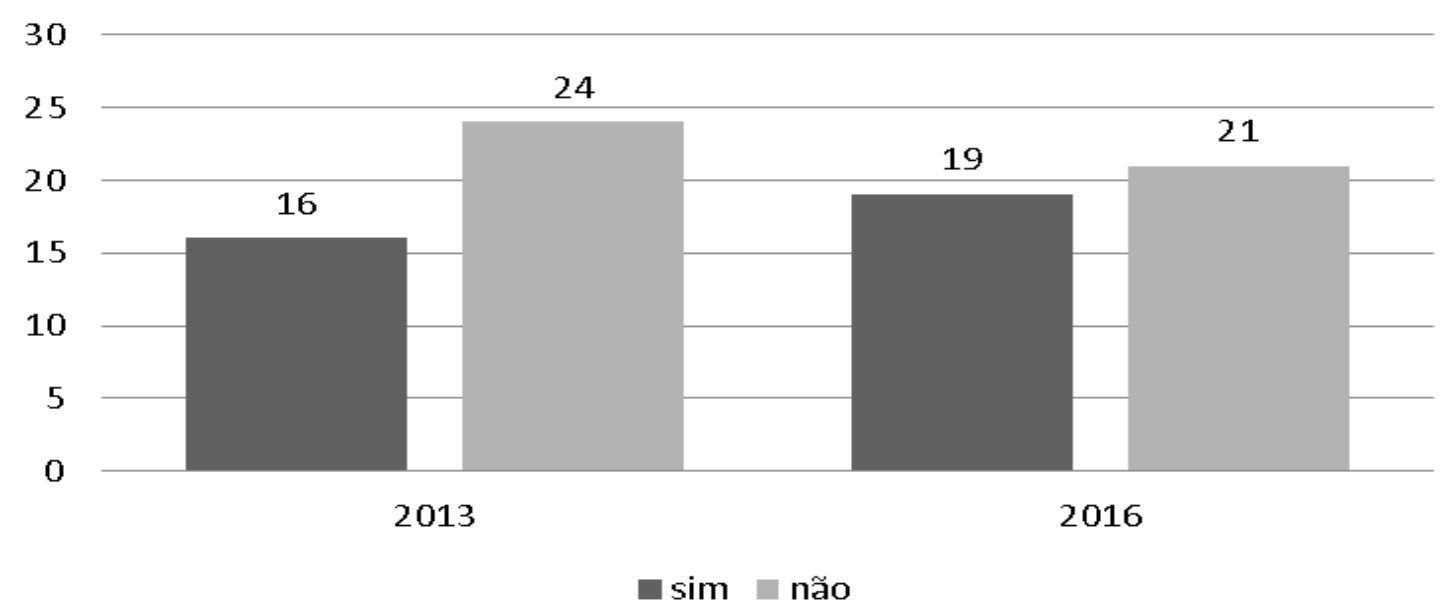

Figura 2: Uso de medicamentos por parte de condutores.

Ao serem questionados para identificar qual o medicamento mais utilizado, resultou que seis $(7,5 \%)$ fazem uso de Valsartana; cinco $(6,25 \%)$ Propanolol; nove $(11,25 \%)$ Captopril; seis (7,5\%) Losartana; um (1,25\%) Hidrocloratiazida; um (1,25\%) Glibencamida; cinco $(6,25 \%)$ Metformina; e dois (2,5\%) Alprazolan, como se pode observar no gráfico da figura 3:

\section{Medicamentos}

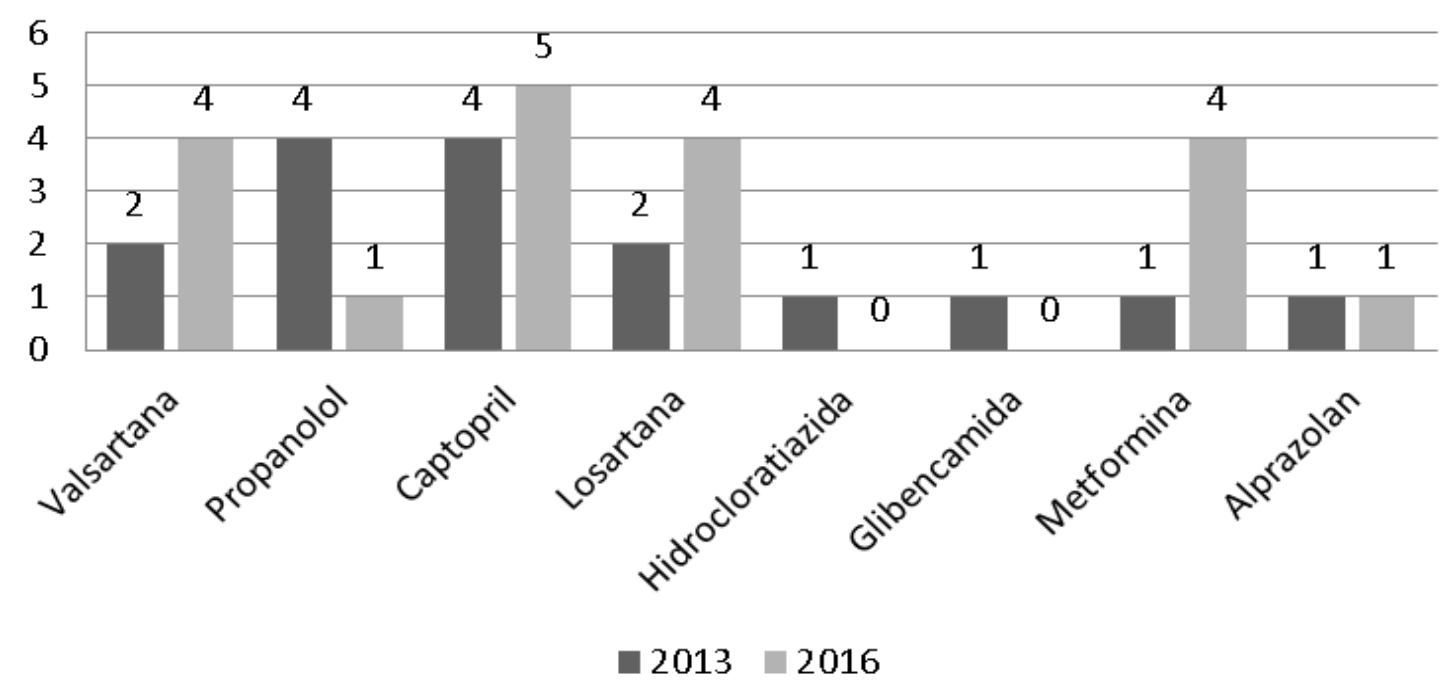

Figura 3: Medicamentos mais utilizados por condutores.

Ao serem questionados se fazem uso de bebida alcoólica, 52 (65\%) entrevistados responderam positivamente e 28 (35\%) afirmaram não fazer uso, segundo o gráfico da figura 4 : 


\section{Uso de bebidas álcoolicas}

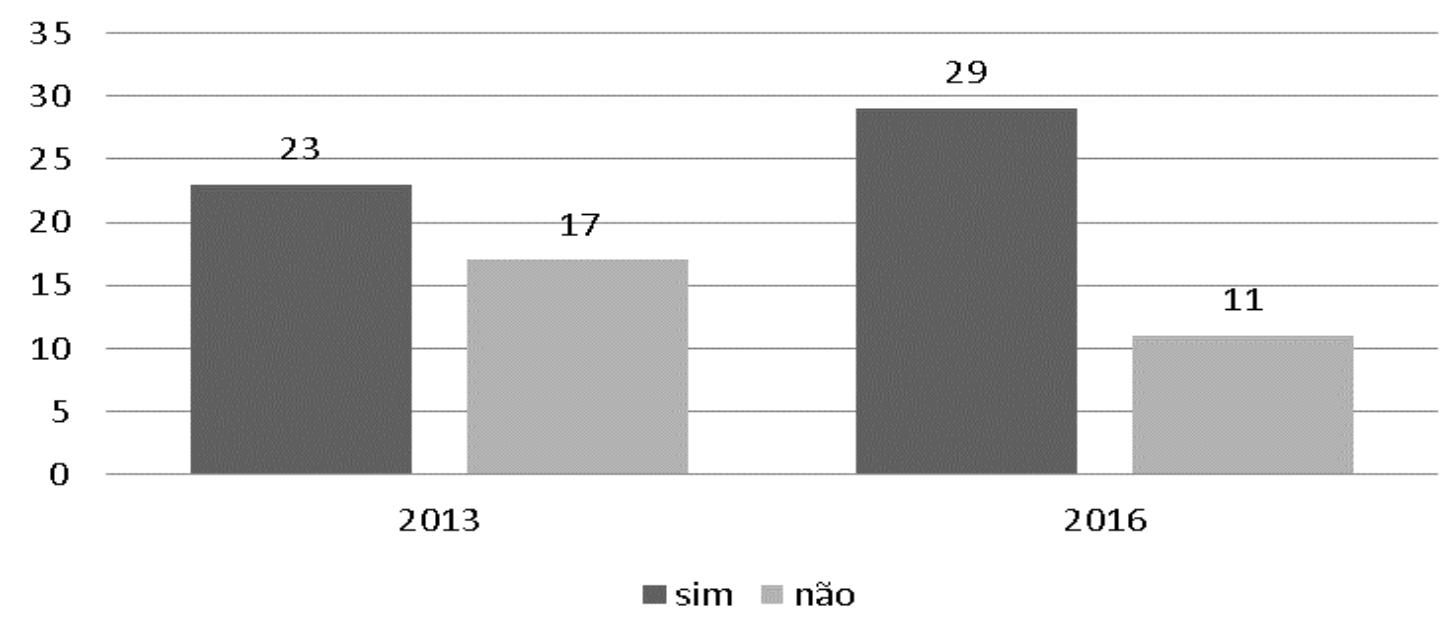

Figura 4: Uso de bebida alcoólica de forma frequente.

Ao perguntar sobre o local que é feito o consumo de bebidas alcoólicas, foi obtido que 14 $(17,5 \%)$ fazem uso em casa; $18(22,5 \%)$ em um bar; e $20(25 \%)$ responderam que em casa e em bares, conforme o gráfico da figura 5 nos mostra:

\section{Local de consumo}

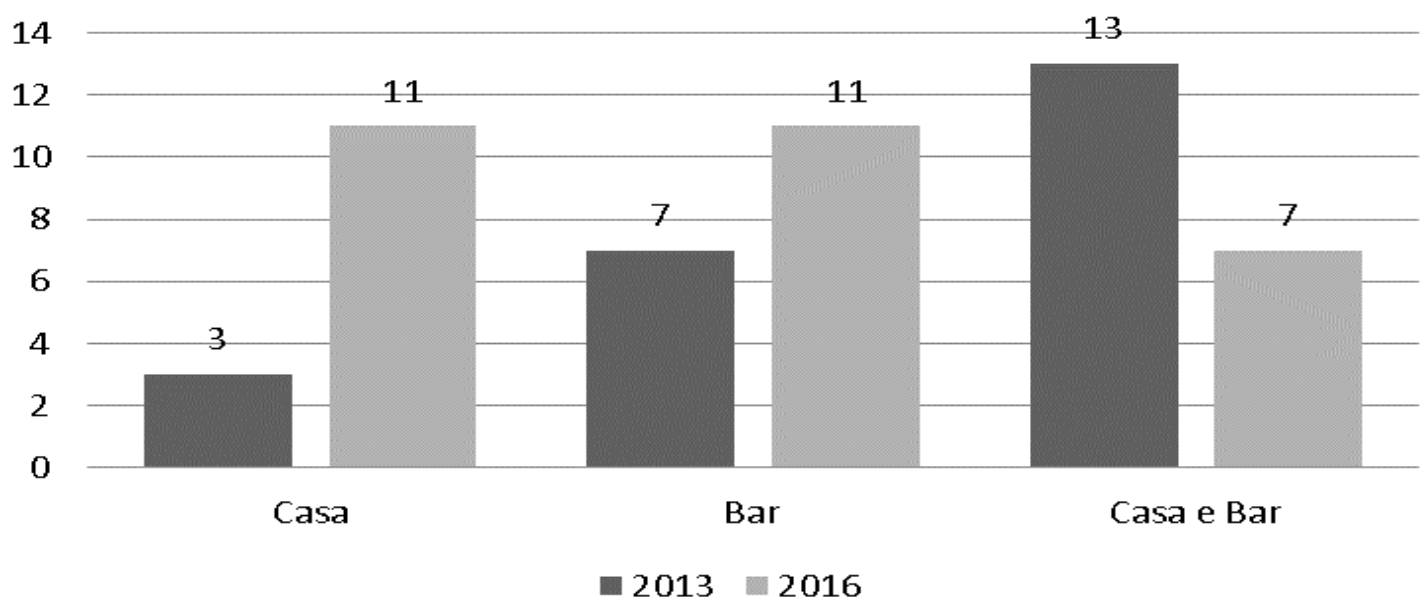

Figura 5: Local de consumo de bebidas alcoólicas por condutores.

Com relação à frequência que fazem uso de bebida alcoólicas, oito (10\%) responderam diariamente; $19(23,75 \%)$ bebem uma vez por semana; 16 (20\%) entre 2 e 3 vezes por semana; e nove $(11,25 \%)$ entre 4 e 5 vezes por semana, diante do gráfico da figura 6 : 


\section{Frequência do uso de bebidas}

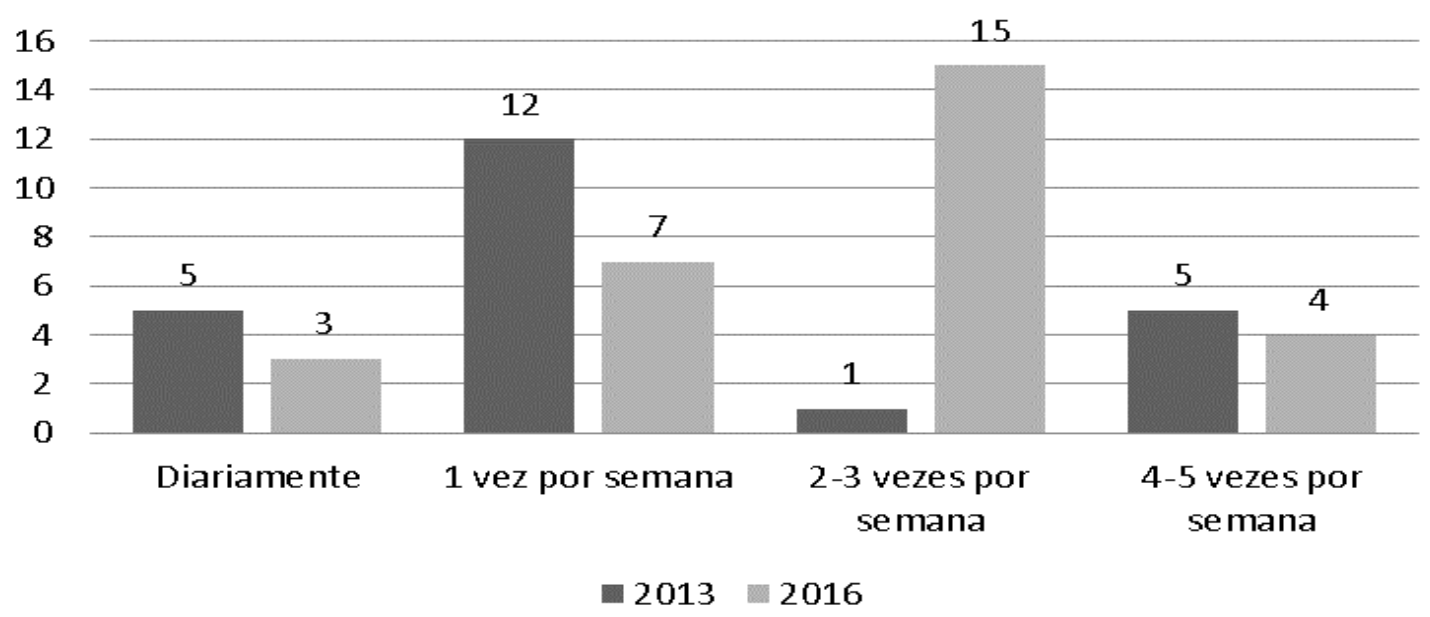

Figura 6: Frequência de consumo de bebida alcoólica por condutores.

Em relação aos hábitos tabagistas, 24 (30\%) se declararam fumantes e 56 (70\%) não fumantes, conforme elucidado pelo gráfico da figura 7 :

\section{Fumantes}

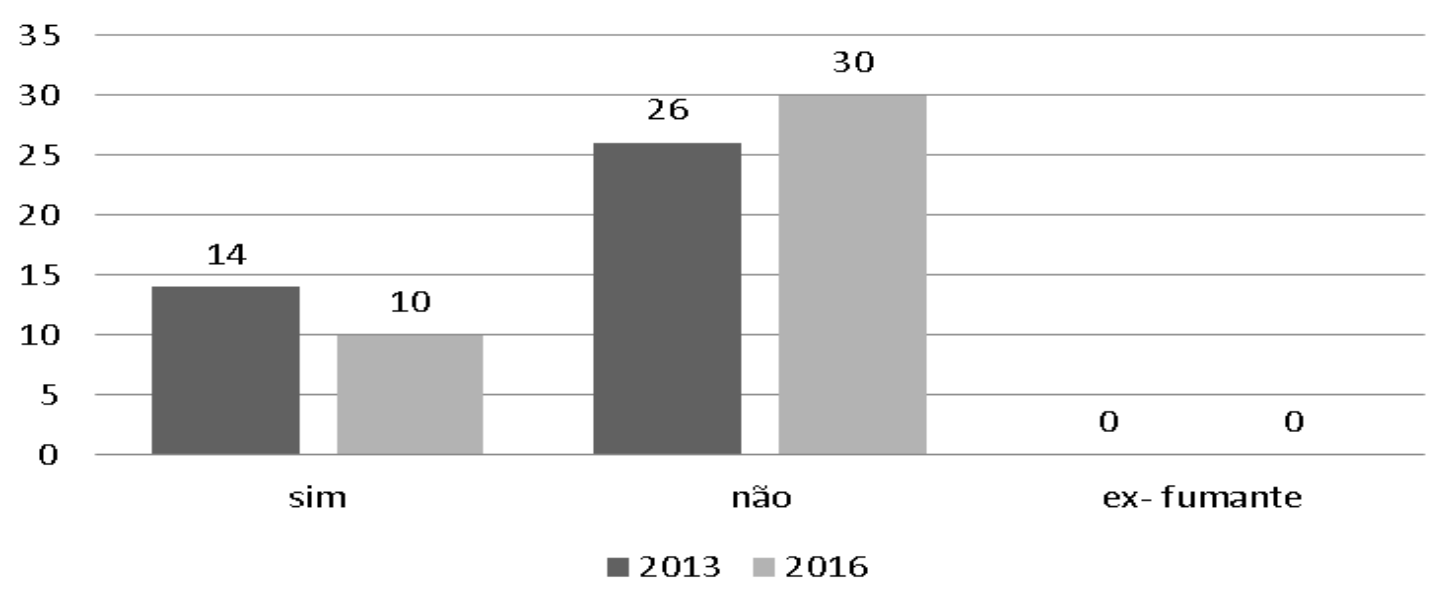

Figura 7: Relação sobre o uso de cigarro.

Como variável principal sobre o uso de rebite, no ano de 2013, 31 (77\%) os condutores afirmaram usar; oito (20\%) responderam negativamente; e um (3\%) disse já ter feito uso. Em 2016, $24(60 \%)$ responderam afirmativamente: $13(33 \%)$ responderam que não; e três $(7 \%)$ disse já ter feito uso, conforme o gráfico da figura 8 : 


\section{Faz uso de rebites}

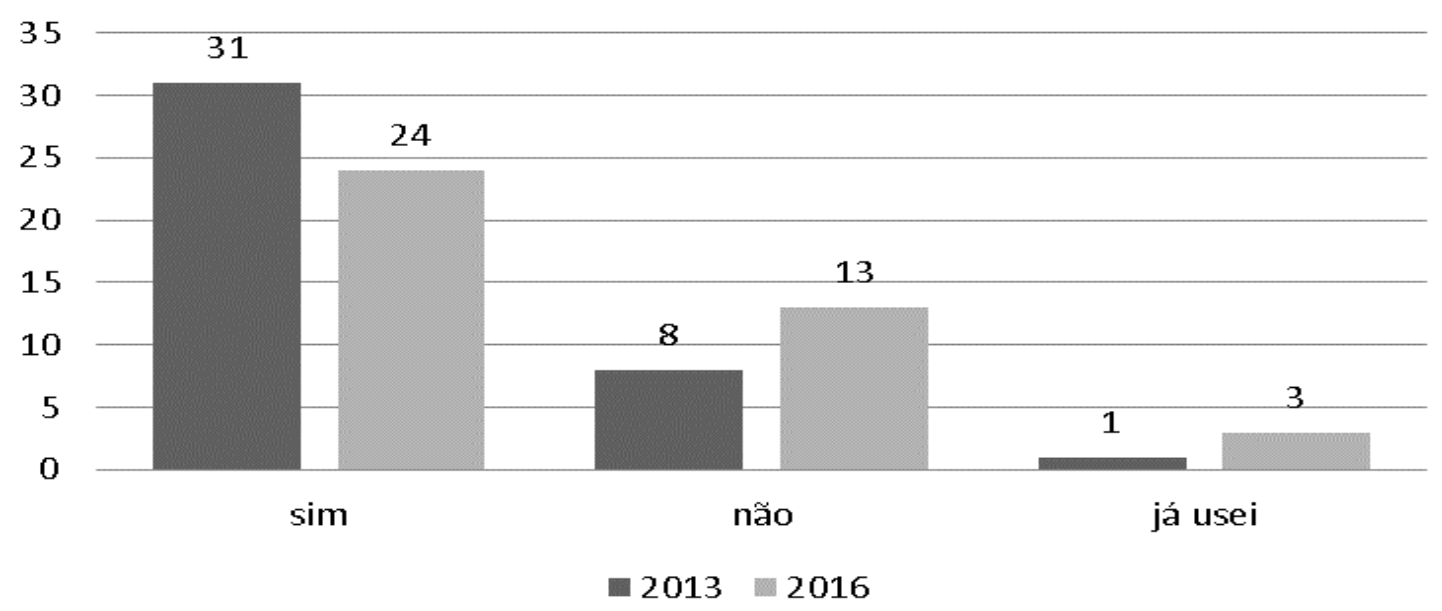

Figura 8: Relação entre o uso de rebites (anfetaminas) por condutores. Valores de ANOVA F calculado 2,232 F crítico 0,309 (valor- $P=0,0127$ ) entre os grupos; F calculado 25,935 e F crítico 9,552 (valor- $P=0,784$ ) dentro dos grupos, sendo teste de TUKEY Sim (a), Não (b) e já usei (c) com IC (95\%).

Tendo em vista a utilização de anfetaminas como rebites por parte de condutores observouse quais os principais princípios ativos mais se apresentavam, tendo em vista o gráfico a figura 9:

\section{Anfetaminas utilizadas}

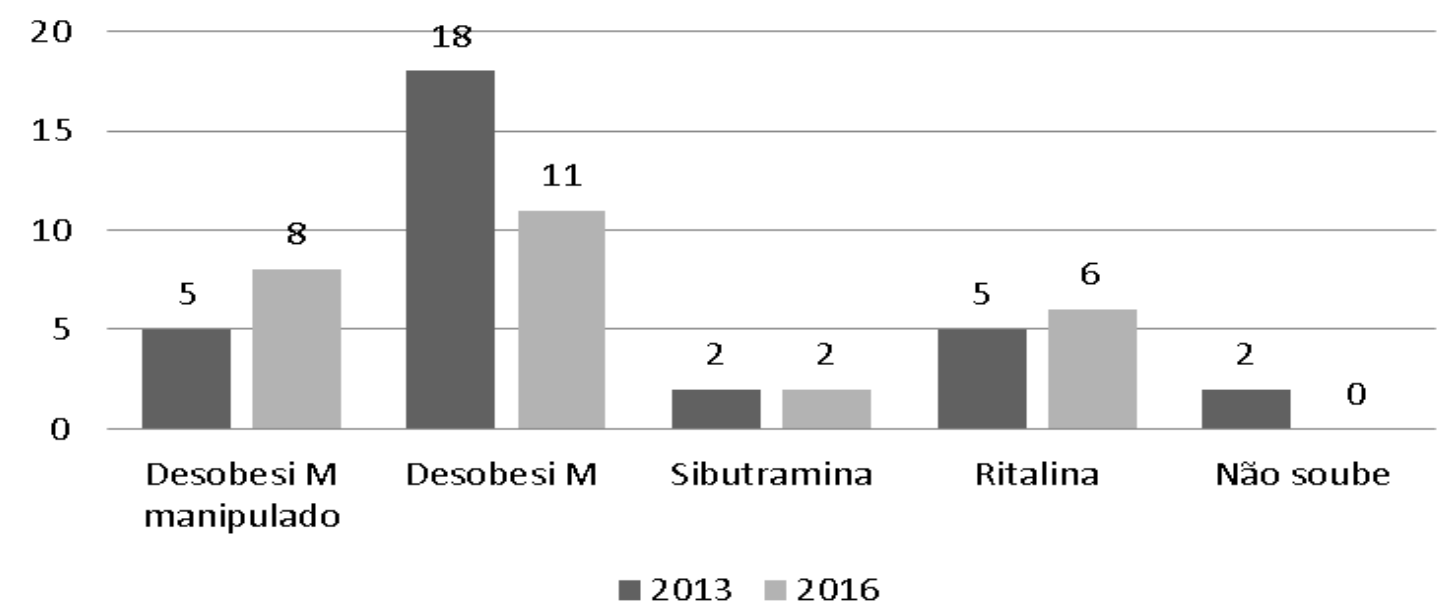

Figura 9: Substâncias mais utilizadas como rebite. Valores de ANOVA F calculado 0,078 F crítico 5,371 (valor- $P=$ 0,787) entre os grupos; F calculado 9,023 e F crítico 5,194 (valor- $P=0,0162$ ) dentro dos grupos, sendo teste de TUKEY Desobesi ${ }^{\circledR}$ (a), e demais (b) IC (95\%).

A partir da descrição dos principais fármacos anfetamínicos utilizados por condutores determinou-se a frequência e periodicidade em que tais ações eram repetidas. Para tal, descreveram-se os dados obtidos no gráfico da figura 10: 


\section{Frequência do uso de anfetaminas}

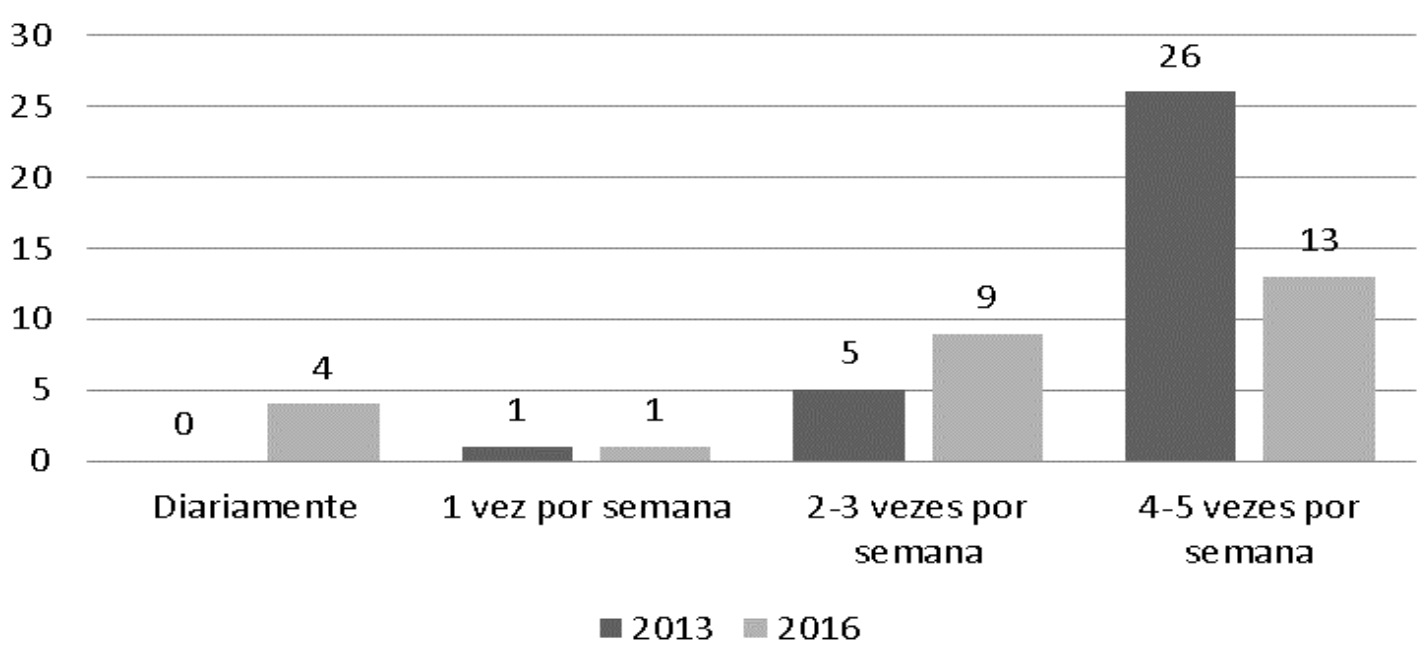

Figura 10: Frequência na utilização de rebites em condutores Valores de ANOVA F calculado 5,626 e F crítico 9,279 (valor- $P=0,1023$ ) entre os grupos; F calculado 76739,4 e F crítico 5,192 (valor- $P=0,00003$ ) dentro dos grupos, sendo teste de TUKEY 4-5 vezes por semana (a), 2-3 vezes por semana (b), demais (c) IC (95\%).

Ao descrever o local de compra dessas anfetaminas, conclui-se que mais de $70 \%$ foi obtida em postos de gasolina. Conforme o gráfico da figura 11:

\section{Origem das anfetaminas}

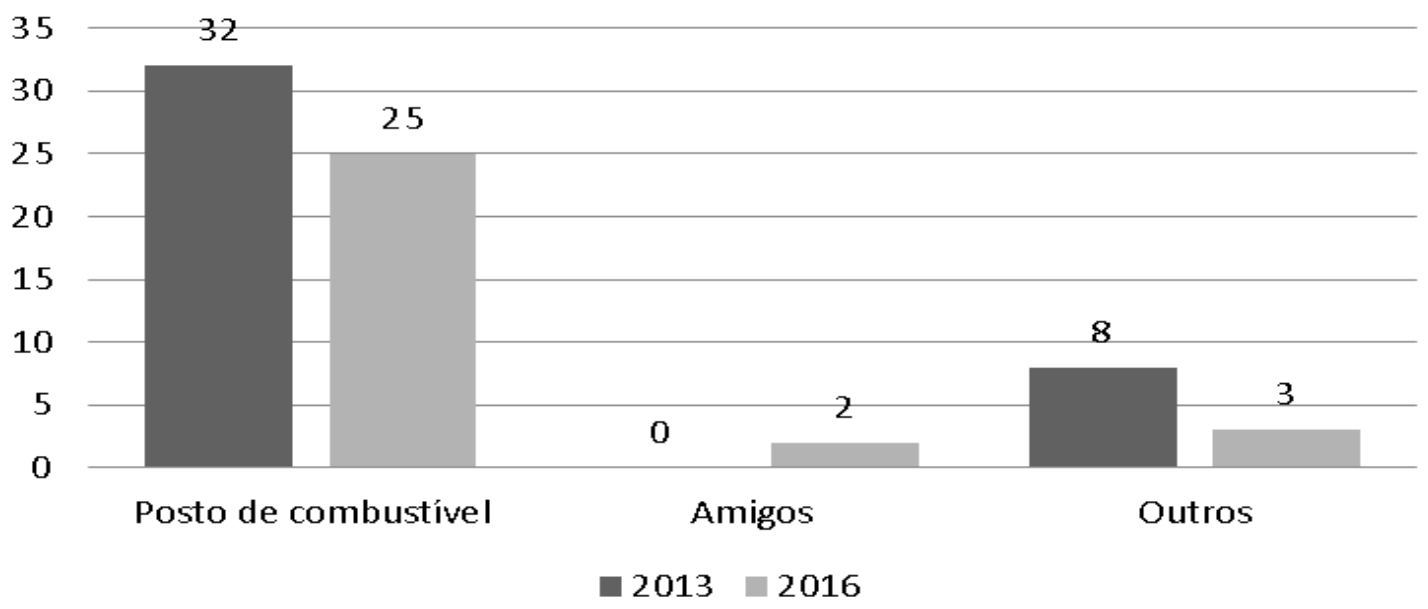

Figura 11: Local de compra das anfetaminas. Valores de ANOVA F calculado 5,749 e F crítico 6,591 (valor$P=0,0621$ ) entre os grupos; F calculado 59,226 e F crítico 9,552 (valor- $P=0,00382$ ) dentro dos grupos, sendo teste de TUKEY Postos de Gasolina (a) e demais (b) IC (95\%).

Em relação aos motivos da utilização de anfetaminas obteve-se: Manter acordado se torna como o principal motivo para uso, $73,75 \%$ afirmou, e os demais responderam ter outros motivos. Conforme o gráfico da figura 12 nos mostra: 


\section{Motivos para o uso}

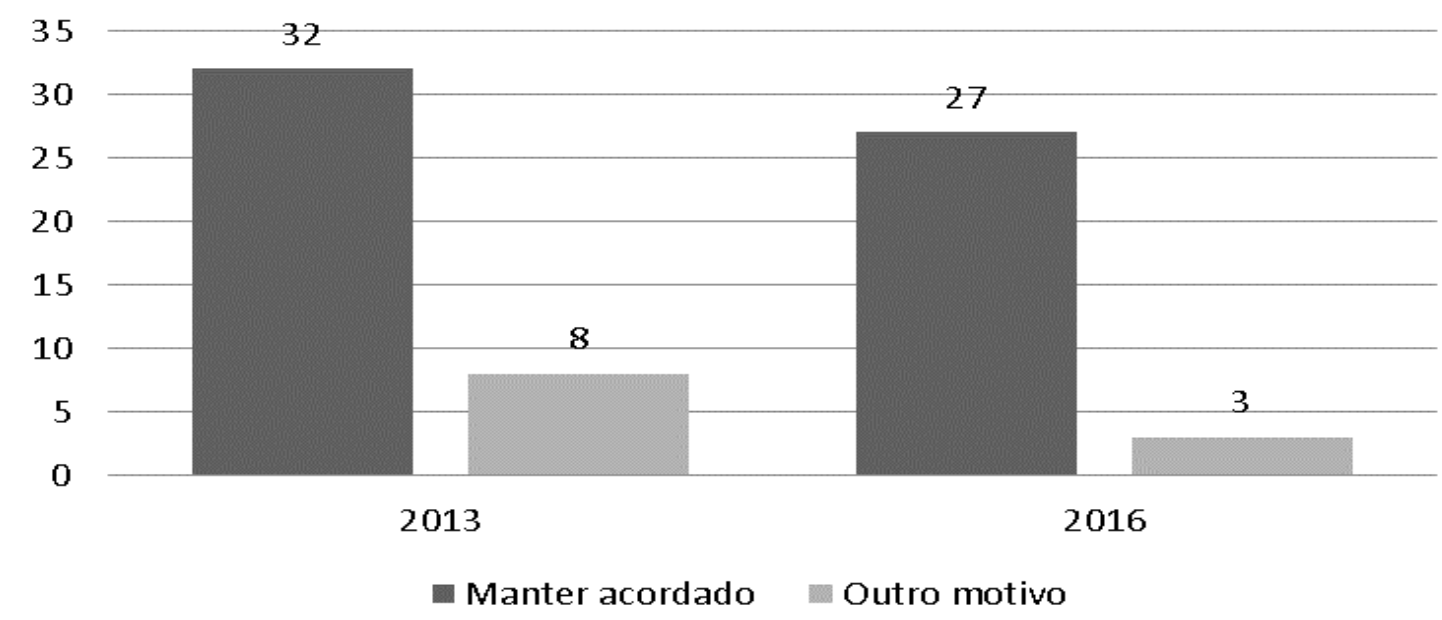

Figura 12: Motivos para o uso. Valores de ANOVA F calculado 0,014261 e F crítico 18,512 (valor- $P=0,9158$ ) entre os grupos.

\section{Discussão}

As anfetaminas são aminas simpaticomiméticas, que produzem efeitos estimulantes poderosos sobre o sistema nervoso central (SNC), ocasionando também ação adrenérgica periférica e central. Os psicoestimulantes compreendem um grupo de drogas de várias estruturas, que aumentam a atividade motora e reduzem a necessidade de sono, diminuindo a fadiga, induzindo a euforia e apresentando efeitos simpaticomiméticos, ou seja, aumentando as ações do sistema nervoso simpático (ZEFERINO, 2004).

Ao estimular o SNC, as anfetaminas levam o cérebro a trabalhar mais depressa, ocasionando uma redução do sono e deixando o indivíduo mais "elétrico, sendo chamada de "rebite" entre os motoristas e de "bolinha" por estudantes".

A anfetamina, com seu isômero dextrogiro ativo, a dextroanfetamina, a metanfetamina e o metilfenidato, formam um grupo de substâncias que possuem propriedades farmacológicas muito semelhantes, onde estão incluídas as chamadas drogas de rua, como o metilenodioximetanfetamina, também denominado, respectivamente de NDMA, MDA ou mais popularmente, o ecstasy (RANG; DALE, 2011).

Segundo estudos, verificou-se que $66 \%$ dos caminhoneiros costumavam fazer uso de anfetaminas durante o percurso de viagem (NASCIMENTO; NASCIMENTO; SILVA, 2007). Para tal fato, pode-se observar no gráfico 8 (Relação entre o uso de rebites (anfetaminas) por condutores) que $31(77,5 \%)$ condutores relataram o uso em 2013 e 24 (60\%) em 2016, com prevalência de $68,75 \%$ dentre esses anos. Isso nos mostra que apesar da redução do consumo entre 2013 e 2016, a prevalência do consumo ainda se mostra com leve aumento em relação ao estudo realizado em 2007. Além disso, o gráfico 9 nos mostra que a anfetamina mais comumente procurada é o Desobesi $\mathrm{M}^{\circledR}$, também citado como o mais consumido no trabalho de Cerqueira et al. (2011).

Considerando o estudo de Nascimento, Nascimento e Silva (2007), onde 27\% dos caminhoneiros usavam anfetaminas diariamente e $60 \%$ de duas a três vezes por semana. Pode-se notar que no gráfico 10 (Frequência na utilização de rebites em condutores) existe $0(0 \%)$ que usavam diariamente em 2013 e $4(14,81 \%)$ em 2016, enquanto $5(15,63 \%)$ motoristas usavam de duas a três vezes por semana em 2013 e 9 (33,33\%) em 2016, demostrando assim a ocorrência de uma mudança na frequência do abuso de anfetaminas, tendo uma prevalência de $64,7 \%$ para o uso de quatro a cinco vezes por semana, contemplando os anos de 2013 e 2016. 
Resultados obtidos por Moreira e Gadani (2009), os quais concluíram que $65 \%$ dos entrevistados usam rebite, e destes $57 \%$ informaram ter conhecimento das consequências de seu uso, entretanto, devido ao medo em perder o frete, pois caso haja recusa em cumprir o horário outro caminhoneiro assume o serviço, levando a perda de trabalhos e risco de não ser contratado pelas empresas, devido a isso muitos se arriscam em longas horas de viajem sobre efeito de tais substancias.

Em uma pesquisa envolvendo motoristas de caminhão do estado de São Paulo, 12,3\% relataram ter hipertensão, 7,7\% estresse e 4,6\% diabetes (TAKITANE et al., 2013). Considerando o estudo, o gráfico 1 desta pesquisa aponta que na média dos anos de 2013 e 2016 encontra-se 27 $(33,75 \%)$ motoristas apresentando hipertensão, 7 (8,75\%) estresse e $6(7,5 \%)$ diabetes. Indicando assim, que as comorbidades envolvendo a profissão são comuns, devido a fatores que interferem na qualidade de vida dos motoristas de caminhão, dentre eles, o abuso de substâncias como as anfetaminas.

Pesquisa realizada pela Confederação Nacional de Transporte (CNT, 2016), por meio da entrevista de 1066 caminhoneiros (autônomos e empregados de frota) no período de 4 a 14 de novembro de 2015, afirma que dentre os entrevistados 24,0\% utilizam ou já utilizaram medicamento controlado, sendo que a maioria destes $(57,7 \%)$ para o controle da hipertensão arterial, corroborando os dados obtidos neste trabalho, na qual a hipertensão é uma comorbidade bastante frequente $(33,75 \%)$ na vida desses profissionais. No entanto de acordo com a CNT, dentre os problemas médicos que o caminhoneiro já teve ou tratou, os problemas de coluna são os mais citados $(16,2 \%)$, seguida da hipertensão arterial $(11,0 \%)$.

Ainda considerando o estudo de Takitane et al. (2013), em relação uso de drogas, 66,2\% declararam-se não fumantes, $10,8 \%$ ex-fumantes e 23,1\% fumantes, além disso, 69,2\% dos participantes relataram o uso de álcool. Tendo essa realidade, o gráfico 7 desta pesquisa nos mostra que em 2013, 65\% dos motoristas são não fumantes e 35\% fumantes, enquanto que em 2016, $75 \%$ são não fumantes e $25 \%$ fumantes, sendo que em ambos os anos não houve relato de ex-fumantes, além disso, o gráfico 4 apresenta em 2013 que 57,5\% dos condutores faziam uso de álcool e que em 2016 a taxa de abuso aumentou para 72,5\%. Isso mostra um perfil similar entre os motoristas de caminhão quanto ao abuso dessas drogas, já que as condições de trabalho são semelhantes, apesar das pesquisas serem em regiões diferentes do país.

$\mathrm{O}$ uso de anfetaminas adquiridas em postos de combustíveis foi de $62 \%$ na cidade de Dourados-MS (MOREIRA; GADANI, 2009). Enquanto que o trabalho de Nascimento, Nascimento e Silva (2007), nos mostra que em Passos-MG, 54\% dos motoristas de caminhão usavam anfetaminas originadas de postos de combustíveis. Logo, observa-se no gráfico 11 deste estudo que a prevalência da obtenção de anfetaminas nos anos de 2013 e 2016 dessa origem é cerca de $82 \%$. Portanto, verifica-se um aumento significativo de motoristas adquirindo anfetaminas em postos de combustíveis, o que representa uma facilidade de aquisição ilegal dessas substâncias.

Corroborando as informações supracitadas, de acordo com dados do perfil dos caminhoneiros 2016 (CNT, 2016), estes profissionais relataram com maior frequência a oferta de substancia ou droga ilícita para trabalhar nos postos de abastecimento $(35,3 \%)$, sendo o rebite a droga mais oferecida $(87,7 \%)$.

Com o advento da resolução 50/2014 da ANVISA a ilegalidade e informalidade da comercialização dessas drogas têm aumentado e sites passam a oferecer cada vez mais produtos com entrega rápida sem apresentação de receituário médico. Como sites que apresentam forma de adquirir clandestinamente tais produtos pode-se citar como exemplos: webcomercios.com.br, emagrenutre.com.br e anabolizantesmaromba.com.br. Os preços variam de 90 a 140 reais em diversas marcas, muitos sem apresentação da empresa e somente no "blister" sem caixa ou lacre ou selo de qualidade trazendo dúvida sobre a procedência e garantia da qualidade dos mesmos. 
Ainda assim, são vários os reclamantes em relação à garantia da entrega do produto, sendo muitos apresentando como fraude comercial (BRASIL, 2014).

Ainda como ponto de discussão, temos o contrabando de anfetaminas via Paraguai, uma vez que de acordo com os órgãos de regulamentação do país tais medicamentos possuem venda livre sem a necessidade de retenção ou apresentação de receitas. Dentro do âmbito nacional esse crime é descrito como delito de contrabando de medicamentos e está tipificado no art. $273, \S 1^{\circ} \mathrm{e}$ $1^{\circ}$-B, do Código Penal, Decreto-Lei n ${ }^{\circ} 2.848$, de 7 de dezembro de 1940. Mesmo histórico passou o medicamento Dualid ${ }^{\circledR}$ quando proibido em 2011 no Brasil e vendido largamente no Paraguai até hoje, como pode-se observar sua comercialização no site www.lojasnoparaguai.com.br/dualid. Sendo possível visualizar essa situação de contrabando em uma das ações da Polícia Rodoviária Federal (2016), que apreendeu cerca de 60 mil comprimidos de anfetaminas, sendo a carga ilícita de origem Paraguaia tendo Vitória da Conquista (BA) como possível destino.

Visando promover uma redução no abuso de anfetaminas e consequentemente os óbitos em decorrência do uso de drogas, a Lei $N^{\circ}$ 13.103, de 2 de março de 2015 colocou a obrigatoriedade da realização de exames toxicológicos para os motoristas profissionais.

\section{Conclusão}

Pode-se dizer que com os resultados obtidos através da pesquisa, que não ocorreu uma redução significativa da prevalência do uso de anfetaminas entre os anos de 2013 e 2016. Sendo assim, percebe-se que mesmo com a criação da lei que delimita a comercialização de anfetaminas, a RDC 50/2014, que dispõe sobre as medidas de controle de comercialização, prescrição e dispensação de medicamentos que contenham as substâncias anfepramona, femproporex, mazindol e sibutramina, seus sais e isômeros, bem como seus intermediários, o consumo de tais substancias ainda permanece elevado.

Assim sendo, esperava-se uma redução na utilização de anfetaminas, entretanto, ainda existe um forte abuso dessa classe de medicamentos junto aos condutores de carga pesada. Demonstrando que a ilegalidade e a obtenção de produtos no âmbito do uso irracional ainda se mostram presente no cenário descrito pelo cotidiano desta categoria profissional, entretanto, a Portaria 116 do Ministério do Trabalho de 2015 visa a exigência de exames toxicológicos para esses profissionais com o intuído de desencorajar o abuso de substâncias lícitas e ilícitas que afetam a dirigibilidade.

\section{Referências}

BRASIL. Presidência da República. Decreto-Lei $\mathbf{n}^{\mathbf{0}} \mathbf{2 . 8 4 8}$, de $\mathbf{7}$ de dezembro de 1940. Disponível em: <http://www.planalto.gov.br>. Acesso em: 11 nov. 2016.

BRASIL. Presidência da República. Lei $\mathbf{n}^{\mathbf{0}}$ 13.103, de 2 de março de 2015. Disponível em: <http://www.planalto.gov.br>. Acesso em: 11 nov. 2016.

BRASIL. RDC n ${ }^{\circ}$ 50, de 25 de julho de 2014. Resolução da Diretoria Colegiada - RRDC No 50, de 25 de Setembro de 2014.

CERQUEIRA, Gilberto Santos et al. Uso de anfetaminas entre caminhoneiros: um estudo transversal. RevInter (Revista Intertox de Toxicologia, Risco Ambiental e Sociedade), [s. L.], v. 4, n. 2, p.76-86, jun. 2011.

CNT. Pesquisa CNT de perfil dos caminhoneiros 2016. Brasília: CNT, 2016. 
HIRATSUKA, A. Análises de impactos ambientais e econômicos em transporte multimodal. 2009. 85 f. Dissertação (Mestrado) - Faculdade de Engenharia, Universidade Estadual Paulista, Ilha Solteira, 2009.

KNAUTH, Daniela Riva. Manter-se acordado: a vulnerabilidade dos caminhoneiros no Rio Grande do Sul. Rev Saúde Pública, Pelotas, v. 5, n. 46, p.886-893, maio 2012.

MOREIRA, Renata Silva; GADANI, Julice Angélica Antoniazzo Batistão. A Prevalência do Uso de Anfetaminas por Caminhoneiros que Passam pela Cidade de DouradosMS. Interbio, Dourados, v. 3, n. 2, p.27-34, dez. 2009.

NASCIMENTO, Eurípedes Costa do; NASCIMENTO, Evania; SILVA, José de Paula. Alcohol and amphetamines use among long-distance truck drivers. Revista de Saúde Pública, [s.1.], v. 41, n. 2, p.290-293, abr. 2007. FapUNIFESP (SciELO). http://dx.doi.org/10.1590/s003489102007000200017.

POLÍCIA RODOVIÁRIA FEDERAL. PRF apreende 60 mil comprimidos de anfetaminas. 2015. Disponível em: <https://www.prf.gov.br>. Acesso em: 11 nov. 2016.

RANG, H P; DALE, M M. Farmacologia. Londres: Elsevier, 2011. 768 p.

TAKITANE, Juliana et al. Uso de anfetaminas por motoristas de caminhão em rodovias do Estado de São Paulo: um risco à ocorrência de acidentes de trânsito? Ciência \& Saúde Coletiva, [s.1.], v. 18, n. 5, p.1247-1254, maio 2013. FapUNIFESP (SciELO). http://dx.doi.org/10.1590/s141381232013000500009 .

WENDLER, E. A. et al. Uso de anfetaminas por motoristas de caminhão para reduzir o sono. Revista Saúde, Ponta Grossa, v. 9, n. 314, p.7-14, 2003.

ZEFERINO, M.T. Acidentes de trânsito e os estimulantes do tipo anfetaminas: estudo de caso junto às empresas de transporte rodoviário de cargas no estado de Santa Catarina. Texto \& Contexto Enfermagem, Florianópolis, v. 14, n. 3, 2005. 